\title{
Adaptation of the CarFreeMe driver retirement intervention to provide driving cessation support to older people living with dementia
}

\author{
Theresa L. Scott ${ }^{1,}\left(\right.$ (D) Jacqueline Liddle ${ }^{1,2}$ (D), Raychelle Sidhu ${ }^{1}$, Geoffrey Mitchell ${ }^{3}$ (D), \\ Elizabeth Beattie ${ }^{4}$ (D) Louise Gustafsson ${ }^{5}$ (i) and Nancy A. Pachana ${ }^{1}$ (D) \\ ${ }^{1}$ School of Psychology, The University of Queensland, Brisbane, QLD, Australia, ${ }^{2}$ School of Information Technology and \\ Electrical Engineering, The University of Queensland, Brisbane, QLD, Australia, ${ }^{3}$ Primary Care Clinical Unit, Faculty of \\ Medicine, The University of Queensland, Brisbane, QLD, Australia, ${ }^{4}$ Dementia Centre for Research Collaboration, School \\ of Nursing, Queensland University of Technology, Brisbane, QLD, Australia and ${ }^{5}$ School of Allied Health Sciences, \\ Griffith University, Brisbane, QLD, Australia \\ *Corresponding author. Email: theresa.scott@uq.edu.au
}

(Received 04 October 2019; revised 20 August 2020; accepted 10 September 2020; first published online 15 October 2020)

\begin{abstract}
Objective: Driving and stopping driving present challenging issues for older people living with memory problems and the family members supporting them. Changes to driving status impact the individual stopping driving and their family members. CarFreeMe is an existing, effective driving cessation program for older people that may be applicable to older people living with dementia. The purpose of this study was to adapt the program and explore feasibility and key stakeholder perspectives.

Methods: The Medical Research Council guidelines for conducting research into complex interventions guided the development, acceptability and feasibility piloting. A multidisciplinary approach was taken, and key stakeholders were involved throughout the process. This included an adaptation process, followed by expert reference group feedback and case series pilot study.

Results: The background research indicated that some key changes were required to meet the needs of people living with dementia. Aspects of the content, language, format and activities were adapted and an additional module was created for family members - whose involvement was identified as important. A more personalized, flexible approach was recommended. The expert reference group [psychologists $(n=2)$, occupational therapists $(n=3)$ and dementia behavior consultants $(n=2)]$ indicated the program was appropriate and needed, and made recommendations for feasibility. Pilot testing with three families indicated acceptability.

Conclusion: A driving cessation program adapted for use with people living with dementia and their families required some changes to meet the needs and situations based on feedback from key stakeholders. Future studies will evaluate implementation outcomes across a range of settings.
\end{abstract}

Keywords: Dementia; driving; driving cessation; older adults; intervention; support; mobility

\section{Background}

Driving is a complex behavior. Dementia can have a profound effect on a person's capacity for driving, impacting decision making, including when to cease driving. At some point, all people with dementia will have to give up driving and rely on alternative transportation options to access the community. Driving cessation can be an overwhelming life transition for people living with dementia and their family members. Loss of driving may limit access to activities outside of home 
and the loss of a pleasurable activity in driving itself, making the person more vulnerable to depression (Baker, Bodner \& Allman, 2003; Choi \& DiNitto, 2015). Furthermore, restriction in movement beyond the home is linked with increased chronic illness (Baker et al., 2003), frailty (Xue et al., 2008) and more rapid cognitive decline(James, Boyle, Buchman, Barnes \& Bennett, 2011). People with dementia, their family members and healthcare professionals describe the enormity of the challenge of stopping, and the need for education to enable awareness, acceptance and planning for driving cessation, together with practical support to encourage continued community engagement (Choi \& DiNitto, 2015; Liddle, Bennett, Allen, Lie, Standen \& Pachana, 2013a; Perkinson et al., 2005). Without intensive practical and emotional support to plan for, and to reduce and eventually cease driving, people with dementia are at risk of isolation (Choi \& DiNitto, 2015). Further, a lack of support can lead to unsafe and unlicensed driving (Hunt, Brown \& Gilman, 2010). Despite the concerns for safety and recognition of the impact of driving cessation on quality of life, health and well-being of people with dementia and their care partners and family members, there are currently no theory-driven, empirically tested interventions to facilitate driving cessation for people with dementia in routine clinical practice within Australia.

An understanding of the reasoning behind a recommendation to stop driving is important for ultimate acceptance of the decision and subsequent coping. Research highlights that such acceptance may be harder for people living with dementia than for older people without cognitive decline, because of lack of awareness of the effects of dementia on driving safety and loss of insight into declining abilities (Scott, Liddle, Pachana, Beattie \& Mitchell, 2019b). Therefore, timing of the decision to stop driving is critically important for people living with dementia. For example, general practitioners (GPs) report that some people with dementia, who are medically assessed as unfit to drive, may refuse their advice and continue to drive, or 'doctor-shop' with the intention of seeking permission to drive from another practitioner (Scott et al., 2019b).

Family members can play a central role in supporting driving cessation decisions and transition. However, the dynamics between family members and individuals with dementia can be complex and accordingly, may adversely impact driving cessation (Liddle et al., 2016; Scott et al., 2019b). Family members may be unsure about when and how to raise the difficult conversation. Their concerns about driving issues may not be supported by health professionals (Liddle et al., 2016). Further, family members may not support the decision to stop driving, such as when they might feel inconvenienced because of a lack of alternative transportation for their family member with dementia (Scott et al., 2019b). The best outcomes are for health professionals and family members to work together to support an individual with dementia in their driving cessation adjustment and continued community mobility.

\section{Driving cessation intervention for older people}

The driving cessation intervention for people living with dementia had been adapted from CarFreeMe (formerly UQDRIVE), a community-based intervention aimed at improving outcomes of driving cessation for older people without cognitive decline. The effectiveness of CarFreeMe has been systematically explored with a general older adult population in a randomized controlled trial (Liddle et al., 2013b). Improvement in community mobility outcomes, self-efficacy (Liddle et al., 2013b), individualized transport and lifestyle goals (Liddle, Hayes, Gustafsson \& Fleming, 2014) and high levels of satisfaction (Gustafsson et al., 2012) have been reported by participants. While CarFreeMe was developed for older people without cognitive impairment, there is a clear need for such an intervention to support people living with dementia and their family members.

\section{Translation to a driving cessation intervention for people living with dementia}

The translated driving cessation intervention was developed in accordance with the four stages of the Medical Research Council guidelines for investigating health-related complex interventions 
(MRC, 2019). Complex interventions are defined as those that are made up of a number of components - parameters of behaviors (frequency, timing) and methods of organizing and delivery (setting, location). This paper reports on the (i) development and (ii) feasibility and piloting stages of the driving cessation intervention for people living with dementia. The third and fourth stages (iii) randomized controlled trial to evaluate a complex intervention and (iv) establishing the long-terms effectiveness of the intervention, are ongoing and planned studies.

\section{Stage 1 development}

\section{Background study}

The preliminary development work that was completed for Stage 1 sought to identify the issues for driving cessation for people with dementia and their carers (Liddle et al., 2013a, 2016). This background study identified through thematic analysis of participant interviews that driving cessation for people living with dementia occurred in stages, each with its own set of challenges and needs for the person with dementia and their family members. The early stage of worried waiting had a focus on building awareness, monitoring safety and getting information and advice about driving and driving cessation. This was followed by a stage of acute adjustment, often involving a crisis or potential crisis in relation to driving or driving cessation. Intensive individualized support was required in terms of managing safety, grief, reducing family conflict and continuing community participation. The post-cessation stage described needs related to ongoing life space restriction, participation and psychological adjustment.

Three principles were identified to guide and shape the development of the dementia-specific program (i) considering persons with dementia and family members (ii) focus on early stage interventions including consideration of potential crises, and (iii) consistent support, flexible and tailored, to each individual. In addition, simplification of language, formatting and examples were made. Principles of supported learning for people living with dementia were also considered (Smith et al., 2011).

The background study informed the adaptation of a seven-module CarFreeMe-People with Dementia intervention (see Table 1). The content, language, format and activities were adapted for people with dementia and an additional module created for family members - whose involvement was identified as a vital aspect of the driving cessation process. For example, module 1 in the original program focused on ageing well and the adapted program focused on living well with dementia.

The CarFreeMe-People with Dementia intervention is designed to be person-centered and flexible, in content and delivery (e.g. in-home, one-to-one, dyads or group settings). As part of the original program design, the intervention is individualized according to geographic location and the needs of participants. For example, older adults are encouraged to consider future transport arrangements, make personal goal-related plans for their lifestyle changes, learn skills to help form realistic expectations and adjust to newly arising challenges after driving cessation, practice using alternative transport, and are supported in their emotional adjustment to the role loss.

The intervention includes seven modules covering education and practical support (e.g. adjustment to changes, alternative transport, lifestyle planning), delivered by a registered health professional (e.g. occupational therapist, psychologist, nurse practitioner, social worker). In the final format, an individualized program may involve a combination of one-to-one sessions, group sessions, practical outings and activities with a local health professional and home-based independent exercises as shown in Table 1.

Stage two of the Medical Research Council guidelines(MRC, 2019) - assessing feasibility and piloting - is described below for the adapted CarFreeMe-People with Dementia intervention. 
Table 1. The content of the original program for older people and the new program for older people living with dementia

\begin{tabular}{|c|c|c|}
\hline Module & Examples of original content/activities & Example of adapted content \\
\hline 1 & $\begin{array}{l}\text { Growing Older: } \\
\text { - Changes with normal ageing; } \\
\text { - Successful ageing strategies }\end{array}$ & $\begin{array}{l}\text { Living With Dementia: } \\
\text { - Living well with dementia; } \\
\text { - Expectations, changes and experiences and } \\
\text { individual issues }\end{array}$ \\
\hline 2 & $\begin{array}{l}\text { Driving Later in Life: } \\
\text { - Driving rights and responsibilities } \\
\text { - Restricting driving and tips for } \\
\text { driving safe; } \\
\text { - Making the decision to stop }\end{array}$ & $\begin{array}{l}\text { Balancing Independence and Safety: } \\
\text { - How dementia affects driving safety; } \\
\text { - Legal requirements and responsibilities; } \\
\text { - Discussion of management of individual } \\
\text { issues }\end{array}$ \\
\hline 3 & $\begin{array}{l}\text { Experiences of Driving Cessation: } \\
\text { - Stages of driving cessation for older } \\
\text { adults; } \\
\text { - Experiences from retired drivers }\end{array}$ & $\begin{array}{l}\text { Experiences of Driving Cessation: } \\
\text { - Shared stories and experiences from } \\
\text { other retired drivers; } \\
\text { - Narrative of own story }\end{array}$ \\
\hline 4 & $\begin{array}{l}\text { Adjusting to Losses and Changes: } \\
\text { - Loss and grief of driving cessation; } \\
\text { - Education about depression; } \\
\text { - Coping strategies }\end{array}$ & $\begin{array}{l}\text { Adjusting to Losses and Changes: } \\
\text { - Grief, depression, and loss of identity } \\
\text { - Problem coping strategies: } \\
\text { - Mindfulness, Problem-focused and } \\
\text { emotion-focused coping; } \\
\text { - Family concerns and coping }\end{array}$ \\
\hline 5 & $\begin{array}{l}\text { Alternative Transport: } \\
\text { - Local transport options; } \\
\text { - Pedestrian safety issues; } \\
\text { - Incorporating group outings: } \\
\text { - Safety audit of local area }\end{array}$ & $\begin{array}{l}\text { Alternative Transport: } \\
\text { - Planning and using appropriate local options; } \\
\text { - Making an individual transport plan for own } \\
\text { destinations and area }\end{array}$ \\
\hline 6 & $\begin{array}{l}\text { Lifestyle Planning: } \\
\text { - Ageing well; } \\
\text { - Setting lifestyle goals; } \\
\text { - Living positively }\end{array}$ & $\begin{array}{l}\text { Lifestyle Planning: } \\
\text { - Future planning; } \\
\text { - Identifying current lifestyle issues including } \\
\text { isolation, unsafe transport; } \\
\text { - Finding meaning, valued roles and } \\
\text { activities }\end{array}$ \\
\hline 7 & $\begin{array}{l}\text { Advocacy and Support: } \\
\text { - Advocacy and advances in transport; } \\
\text { - Providing feedback to local transport } \\
\text { services; } \\
\text { - Forming a local network }\end{array}$ & $\begin{array}{l}\text { Advocacy and Support: } \\
\text { - Introducing advances and ideas in using } \\
\text { alternative transport and staying involved } \\
\text { in life; } \\
\text { - Working through group or individualized } \\
\text { advocacy, and providing feedback to } \\
\text { stakeholders; } \\
\text { - Future planning. }\end{array}$ \\
\hline 8 & $\mathrm{~N} / \mathrm{A}$ & $\begin{array}{l}\text { Family Member/Caregiver: } \\
\text { - Having the conversation; } \\
\text { - Unlicensed driving; } \\
\text { - Coping with caregiving }\end{array}$ \\
\hline
\end{tabular}

\section{Methods}

\section{Research design}

This study used a mixed methods design to explore the appropriateness, feasibility and acceptability of a driving cessation intervention originally targeted at older people that was adapted for people living with dementia. The methods and findings are reported in two parts, (i) content analysis of feedback from health professionals about the feasibility and acceptability of the intervention and (ii) a case series pilot study with people living with dementia and their family members. 


\section{Ethics statement}

This study was approved by The University of Queensland Human Research Ethics Committee, approval number 2013001310. All participants provided informed, written consent.

\section{Health professionals' feedback on CarFreeMe-People with dementia}

Participants

To explore the appropriateness, feasibility and acceptability of the program, an expert reference group of health professionals working with people living with dementia was assembled via purposive sampling. The expert panel consisted of occupational therapists $(n=3)$, psychologists $(n=2)$ and dementia behavior consultants $(n=2)$. All health professionals were females. The number of years of experience in the area of dementia ranged between 2 and 10 years $(M=7.86 ; S D=4.67)$.

\section{Data collection and procedure}

The expert panel reviewed all resources including the seven modules and resource books for the person with dementia and their care partner and were asked to provide ratings on a 10-point Likert type scale, where $1=$ 'not at all satisfied' to $10=$ 'very satisfied'. Data collection involved semi-structured interviews and questionnaires relating to intervention content, resources, structure of the program, delivery and target audience from the expert panel. The panel members completed the ratings scales independently. The semi-structured interviews were conducted by a member of the research team with individual panel members.

\section{Analysis}

Qualitative analysis involved content and thematic analysis of participants' feedback. Descriptive statistics were used to explore their satisfaction ratings of various aspects of the program.

\section{Piloting the CarFreeMe-People with dementia intervention}

\section{Research design}

The program was pilot tested in an intensive case study trial (Yin, 2003). Specifically, the aim of the pilot was to explore feasibility and variants of the intervention and delivery.

\section{Participants}

Participants, persons with dementia and/or care partner/family members, were recruited via dementia support organizations, health professional networks and local media across South East Queensland, Australia. Persons with a clinical dementia rating (CDR; Morris, 1993) of 0.5 'very mild' to 1 'mild' and community-dwelling, were eligible to participate. Family members/care partners who supported a person with dementia who was challenged by driving cessation, were eligible to participate.

The case study participants were:

(1) male (Mr B), aged 88, diagnosed with dementia, a widower, participating with two daughters and currently still driving;

(2) male ( $\mathrm{Mr} \mathrm{L})$, aged 88, diagnosed with dementia and driving, married and participating with his wife who expressed concerns about his driving safety; and

(3) wife (Mrs S) and two daughters of a male (not participating) aged 83 years,diagnosed with dementia, still driving but has been advised by his general practitioner to restrict his driving to the local area. His wife and daughters reported that he was not accepting of his doctor's advice to restrict his driving and that often conflict arose if they had to remind him of this. 
Table 2. Summary of program structure delivered to each dyad or family member

\begin{tabular}{llll}
\hline Session & Case study 1 & Case study 2 & Case study 3 \\
\hline 1 & $\begin{array}{l}\text { Living with dementia } \\
\text { (Module 1) }\end{array}$ & $\begin{array}{l}\text { Safety and responsibilities } \\
\text { as driver (Module 2) }\end{array}$ & $\begin{array}{l}\text { Symptoms of dementia and } \\
\text { lifestyle adjustments (Module 1, 6) }\end{array}$ \\
\hline 2 & $\begin{array}{l}\text { Alternative transport } \\
\text { (Module 5) }\end{array}$ & $\begin{array}{l}\text { Alternative transport, } \\
\text { Lifestyle adjustment } \\
\text { (Modules 5, 6, family) }\end{array}$ & $\begin{array}{l}\text { Driving warning signs, Conversation } \\
\text { strategies, Managing unlicensed } \\
\text { driving (Module 2, 3, family) }\end{array}$ \\
\hline 3 & $\begin{array}{l}\text { Lifestyle planning, Mindfulness } \\
\text { strategies (Modules 3, 4, 6) }\end{array}$ & $\begin{array}{l}\text { Problem-focused and } \\
\text { emotion-focused strategies } \\
\text { (Modules 1, 3, 4) }\end{array}$ & $\begin{array}{l}\text { Coping with caregiving using } \\
\text { problem-focused and emotion- } \\
\text { focused strategies (family, }\end{array}$ \\
& & Module 4) \\
\hline 4 & $\begin{array}{l}\text { Unlicensed driving, Coping with } \\
\text { caregiving, Support services } \\
\text { (Modules 2, 7, family) }\end{array}$ & $\begin{array}{l}\text { Lifestyle planning } \\
\text { (Module 6, 7) }\end{array}$ & Lifestyle planning, Alternative \\
\end{tabular}

\section{Procedure - program delivery}

The intervention was delivered to participants in their own homes by a registered health professional trained in the CarFreeMe for people with dementia program. The first session involved assessment to identify participants' needs and difficulties related to driving cessation. The outline of the flexible program was provided to participants and the order of modules and relevant time spent in each were determined by the health professional, based on the goals set by the participants and their emerging needs. Goal setting, outcome measures and semi-structured interviews were conducted at the first and final sessions. The length of sessions with participants were between 120 and $180 \mathrm{~min}$. A summary of the program structure, personalized to meet the needs of each dyad or family member, is shown in Table 2.

\section{Measurement instruments}

Outcome measures included socio demographic questions; geriatric depression scale (GDS; Yesavage et al., 1982); geriatric anxiety index (GAI; Pachana et al., 2007), and a modified version of the Canadian Occupation (COPM) was used to focus goals on transport and lifestyle considerations as used in the original program trial (Gustafsson et al., 2012). The GDS consists of 30 dichotomous (yes/no) items measuring depressive symptoms across the previous week, higher scores indicate more symptoms. The GAI consists of 20 dichotomous (agree/disagree) items measuring anxiety symptoms, scores of nine and above indicate clinical levels of anxiety. Semistructured interviews explored participants' experiences of the intervention and how well it met their needs.

\section{Analysis}

To illustrate the results of a single-subject case, nonparametric analysis was used to examine the change in pre-post scores on the outcome measures for each case study. Content analysis techniques (Miles \& Huberman, 1994) were used to analyze the participants' experiences of the program.

\section{Results}

\section{Health professional's feedback on CarFreeMe-People with dementia}

The overall satisfaction score with program in this sample displayed a median of 8 out of a possible score of 0 to 10 . The median satisfaction scores with the content, presentation (including workbook, PowerPoint slides and delivery), and relevance of the program to people living with 
Table 3. The level of satisfaction with the newly developed CarFreeMe for people with dementia according to members of the professional reference group

\begin{tabular}{lcccc}
\hline Components & $N$ & Mean & $\begin{array}{c}\text { Interquartile } \\
\text { Range (IQR) }\end{array}$ & Median \\
\hline Overall satisfaction & 7 & 7.5 & $7-8$ & 8 \\
\hline Content & 7 & 7.6 & $7-10$ & 5 \\
\hline Presentation and format & 7 & 7.9 & $5-10$ & 9 \\
\hline $\begin{array}{l}\text { Relevance to people living with } \\
\text { dementia and their families }\end{array}$ & 7 & 8.7 & $6-10$ & 10 \\
\hline
\end{tabular}

dementia and their families ranged from 8 to 10 out of a possible score of 0 to 10 , as shown in Table 3.

The open responses to questions were content analyzed across all participants and formed four key areas: (1) Program necessity; (2) Workbook breadth and detail; (3) Target group and (4) Design and delivery.

All participants $(100 \%, n=7)$ reported that focus on client-centeredness was one of the main strengths of the program. This flexibility allowed the program to be tailored to the varying needs of the individual and helps address urgent or pressing issues. However, they felt that the workbook targeted at people living with dementia and their care partners may have been too long and therefore potentially too overwhelming to participants.

The workbook included experiences of retired drivers with dementia. Regarding these inclusions, respondents were favorable toward brief case study examples and direct quotes. While peer interaction is a direct benefit of group sessions, groups sessions may not always be preferred by or accessible to participants living with dementia, or feasible in the instance of crisis responsive programs. Therefore, as respondents noted, included experiences in the form of quotes would be valuable to the person living with dementia and their family members to help 'comfort' (P01), 'normalize' (P07) and 'learn from other's experiences' (P05).

In the panel's qualitative responses, there was recognition of the need and importance of such a program, for example, 'Driving is more stressful to discuss than the diagnosis itself (P02). There was support for the comprehensiveness of the program, for example,

What's useful is that you're working to a point and I think that's really important, and you're trying to bring the person with dementia along with you in a staged way, as well as educating about dementia within families ... there's still so much misunderstanding, particularly when it comes to behavioural change, so I think that you are trying to bring people along right from the beginning, so that's very useful. (P03).

Respondents commented on whether or not they felt the program was suitable for delivery in a mixed-group format or dyad format (person living with dementia and support person). The general consensus from respondents was that the program may be more effective if it were delivered to dyads and not in groups, given the program targets people living with dementia and the challenges of driving cessation discussions. Health professional expressed that the benefits from sharing peer experiences were already incorporated into the written materials, such as the example quotes from former drivers. While another recommendation was to include a minimum of one group session, along with the individual sessions, so that benefits from discussion and sharing with peers could be attained. The panel determined that the program, while well suited to older people living with dementia, would require further modification to be appropriate for younger people living with dementia. 
Table 4. Participants' pre and post ratings of their self-identified transport and lifestyle goals rated according to the modified COPM (Law, 1998)

\begin{tabular}{|c|c|c|c|c|}
\hline \multirow[b]{2}{*}{ Transport and lifestyle goals } & \multicolumn{2}{|c|}{ Performance } & \multicolumn{2}{|c|}{ Satisfaction } \\
\hline & Pre & Post & Pre & Post \\
\hline \multicolumn{5}{|l|}{ Case study 1: } \\
\hline Increasing engagement in valued activities & 2.00 & 9.00 & 2.00 & 9.00 \\
\hline Finding out various ways of get to club daily & 5.00 & 9.00 & 4.00 & 9.00 \\
\hline Encouraging participation in shared activities & 1.00 & 9.00 & 1.00 & 9.00 \\
\hline Overall average & 2.67 & 9.00 & 2.33 & 9.00 \\
\hline Well-being & Pre & Post & & \\
\hline GDS & 8 & 6 & & \\
\hline GAI & 0 & 0 & & \\
\hline \multicolumn{5}{|l|}{ Case study 2: } \\
\hline Developing alternative transport or means to meet essential travel & 3.00 & 9.00 & 4.00 & 9.00 \\
\hline Increasing knowledge of other transport services & 3.00 & 9.00 & 3.00 & 9.00 \\
\hline Maintenance of desired activities & 5.00 & 8.00 & 5.00 & 9.00 \\
\hline Overall average & 3.67 & 8.67 & 4.00 & 9.00 \\
\hline Well-being & Pre & Post & & \\
\hline GDS & 7 & 2 & & \\
\hline GAI & 1 & 0 & & \\
\hline \multicolumn{5}{|l|}{ Case study $3:$} \\
\hline Knowing the approach to take to encourage driving cessation & 2.00 & 8.00 & 2.00 & 8.00 \\
\hline Assisting family member to stop driving in the next 3 months & 1.00 & 7.00 & 1.00 & 2.00 \\
\hline Putting in place activities for the dyad (retiring driver and partner) & 2.00 & 5.00 & 4.00 & 4.00 \\
\hline Overall average & 1.67 & 6.67 & 2.33 & 4.66 \\
\hline Well-being & Pre & Post & & \\
\hline GDS & 17 & 14 & & \\
\hline GAI & 12 & 18 & & \\
\hline
\end{tabular}

Participants' goals have been paraphrased to maintain anonymity.

Overall, the panel agreed that such a program and training would be highly valued by health professionals and consumers. The recommendations from the reference panel resulted in some changes to the program materials, such as the workbook was shortened to reduce the amount of burden on participants, and planned delivery of the program. The adapted program was pilot tested in an individual mixed-format program (persons with dementia and/or family members), number and content of sessions individualized for the participant, with a minimum of four sessions.

\section{Piloting the CarFreeMe-People with dementia intervention}

\section{Goal setting}

Pre- and post-intervention modified COPM scores for each of three case studies are shown in Table 4. Identifying and setting personally relevant goals is an important feature of the individualized program. Participants, persons with dementia and care partners, were asked to reflect on 
their lifestyle and to identify personally meaningful goals for the program in as specific a way as possible. For example, rather than setting a goal to 'go out more' participants are encouraged to express the goal more specifically, such as, 'to leave the house to attend $\mathrm{X}$ at least once per week'. The health professional's role was to support the participant to identify their current needs and any perceived barriers to achieving particular goals and to problem solve ways to address barriers. For example, if anxiety about using public transport was stopping the participant from leaving the home, then the health professional and participant could work on ways to alleviate the anxiety, including practicing using different modes of public transport. Once participants had identified their goals, with the participants doing this collaboratively, these were rated on the COPM, according to a 10-point scale for performance and satisfaction $(1=$ lowest performance to $10=$ highest performance; $1=$ least satisfied to $10=$ most satisfied; Law, 1998). Goals were related to finding alternative transport and available services, and to emotional and social aspects, as shown in Table 4.

\section{Well-being outcomes}

Case study 1. Involvement in the program resulted in decreases in the level of depressive symptoms for the person with dementia. As shown in Table 4, at post-intervention, Mr B reported improvements in his mood and his confidence to engage in important life activities post cessation. $\mathrm{He}$ and his family acknowledged that involvement in the program brought about greater understanding of dementia and guidance in developing alternative transport and lifestyle planning. Overall, they perceived that having this awareness would make the transition from driver to nondriver easier.

Case study 2. Participation in the program led to a reduction in depressive symptoms and anxiety levels for Mr L (see Table 4). The program had helped him to accept not driving and planning for lifestyle changes. Mr L acknowledged 'age-related changes' as the reason for his driving cessation rather than the effects of dementia. The health professional, in taking a person-centered approach, did not challenge Mr L on his perceived reasons for stopping driving. Mr and Mrs L took part in many social activities and they reported that identifying alternative transport and planning for change were the most helpful aspects of the program.

Case study 3. Participants of case study 3were the wife (Mrs S) and two daughters of a man living with dementia and still driving when they began the program. They reported that discussions about driving cessation often resulted in family conflict or were avoided entirely. The family described driving as an important part of his identity. Mrs S reported that she had benefited greatly from the coping strategies that she learned from module 4 (see Table 1), although she acknowledged that she still needed to practice. Her depressive symptoms decreased from pre- to post-intervention (see Table 4). Although the program had helped her to understand and accept some of the behaviors and the distress that Mr S exhibited, her anxiety levels had increased (see Table 4). Mrs S attributed this increase to stressful life events that had occurred the week prior. Overall, the family felt that they benefited from the program and having knowledge of the steps to take to start discussing driving cessation with their family member. They valued the content and examples from other retired drivers which helped 'normalize' some of their own challenges and negative experiences. However, based on their post-intervention COPM scores (see Table 4), it was clear that there was still more time required for them to resolve some of these driving related issues raised.

\section{Discussion}

Driving cessation can be an overwhelming life transition for people living with dementia, associated with multiple negative consequences for individuals and their family members. 
As dementia progression exacerbates the process of driving cessation, early intervention is vital to enable awareness, acceptance and planning for retirement from driving (Choi \& DiNitto, 2015; Liddle et al., 2013a; Perkinson et al., 2005; Scott et al., 2019b), thus promoting the best possible outcomes for everyone involved.

\section{Acceptability}

Reflecting on the converged findings and health professional's field notes highlighted program acceptability for the range of implementation stakeholders (i.e. health professionals, people with dementia, family members). The findings from people living with dementia who are transitioning to nondriving highlight that acceptability can be affected by awareness and understanding of dementia. Previous research shows that an individual's disease progression, knowledge around how dementia affects driving safety, availability of alternative transports, access to objective assessment of driver safety and identity or role loss can differentially affect an individual's acceptance of driving cessation support (Carr \& O’Neill, 2015; Liddle et al., 2016; Scott et al., 2019b). A flexible approach that considers this aspect is required. In addition, acceptability is shaped by the individualized approach undertaken, and being guided by the individual's goals and current situation. It is clear that reducing family conflict and learning about dementia are key to support coping. However, family members may be unsure about how and when to raise the difficult conversation. Learning a range of coping strategies to find one that works best in a particular situation are important considerations for care partners and family members. It is important that health professionals trained in delivering the CarFreeMe program are also aware of local services and can provide appropriate referrals to such services if needed. If problems remain at program end, there may be a need to provide further support in the form of booster sessions, or referrals for other ongoing supports.

\section{Appropriateness}

The process of driving cessation may be more complex for people living with dementia compared with older people without cognitive decline according to GPs (Scott et al., 2019b), due to lack of insight into one's own driving safety. The program content was perceived as useful and appropriate by health professionals. In addition, the perceived usefulness of an individualized approach and the need for inclusion of basic 'introduction to dementia' information were highlighted. Responsiveness to situations and acting to reduce family conflict and support the family unit were also highlighted as relevant considerations.

There were initial considerations about whether the program was too long for people living with dementia; however, the trial with consumers indicated the importance of more extended contact. Moreover, because of the progressive nature of dementia, some aspects of the content may require revisiting for some, as the disease progresses. Therefore, it may be important to recommend a longer duration of program delivery and a range of shorter sessions with time for embedding changes into life.

\section{Feasibility}

The process of driving cessation involves the individual's wider social network, including their spouse and children (Ang et al., 2020; Liddle et al., 2016).Family members can positively influence driving cessation decisions (Scott et al., 2019b) and are sometimes the sole decision makers (O'Neill et al., 1992). Family involvement in intervention may be critical to achieving goals. Overall, the program was feasible to deliver to a family unit. Flexibility of delivery was highlighted as a key feature of the program (i.e. it was suitable for delivery to a family unit with and without the retiring driver's direct involvement, if needed). Additionally, it is important to be crisis, 
relationship and personal goal responsive (as per the goals of the program). Future work could explore whether combinations of individual, group and family sessions may be helpful.

\section{Limitations and directions for future research}

One limitation of the current study is that case study design, while providing deeper insight, cannot lead to objective conclusions about causality. Evaluation via large, randomized controlled trials is recommended (MRC, 2019). Future research will focus on evaluation of evidence in practice via a randomized controlled trial (Scott, Liddle, Mitchell, Beattie \& Pachana, 2019a) and on establishing the long-term effectiveness of the intervention in settings in which it will be used. Future implementation studies will need to consider real-world variability in effectiveness and cost effectiveness to inform decision-makers, and therefore to effect wide-spread reach and availability of the program to provide needed support to people living with dementia to cope with driving cessation.

\section{Conclusion}

Driving cessation presents challenges for older people living with dementia and their families and for the health professionals who support them. Ceasing to drive is a significant life event associated with a real risk of reduced well-being. The CarFreeMe program described here was developed to (1) facilitate planning for driving cessation in the early stages of dementia, (2) provide support to address the emotional challenges of driving cessation and (3) reduce interpersonal conflict between family members and the person living with dementia relating to driving cessation. Ideally, the program is recommended for people in the early stages of dementia to facilitate active participation in shifting goals; although this may not always be possible, the program can nevertheless assist with adjusting to life without driving and remaining mobile. Where acceptable alternative transport options are limited, lifestyle planning is focused on adapting current patterns to fit the changes in mobility and the impact of dementia. The adapted program is currently being evaluated through clinical trial (Scott et al., 2019a) and future studies will evaluate implementation processes and outcomes. The described adaptation and evaluation method may be applied with other populations experiencing driving cessation.

Acknowledgements. We acknowledge the valuable contribution of the participants in this study.

Financial Support. The first author acknowledges the following financial support for this work provided by the Australian National Health and Medical Research Council and Australian Research Council (ARC), under the Boosting Dementia Research initiative, Grant number 1105924.

Conflict of Interest. Theresa Scott has no conflicts of interest to disclose. Jacqueline Liddle has no conflicts of interest to disclose. Raychelle Sidhu has no conflicts of interest to disclose. Geoffrey Mitchell has no conflicts of interest to disclose. Elizabeth Beattie has no conflicts of interest to disclose. Louise Gustafsson has no conflicts of interest to disclose. Nancy Pachana has no conflicts of interest to disclose.

Ethical Standards. The authors assert that all procedures contributing to this work comply with the ethical standards of the relevant national and institutional committees on human experimentation and with the Helsinki Declaration of 1975, as revised in 2008 .

\section{References}

Ang, B. H., Oxley, J. A., Chen, W. S., Yap, M. K. K., Song, K. P., \& Lee, S. W. H. (2020). The influence of spouses and their driving roles in self-regulation: A qualitative exploration of driving reduction and cessation practices amongst married older adults. PLoS one, 15(5), e0232795. doi: 10.1371/journal.pone.0232795.

Baker, P. S., Bodner, E. V., \&Allman, R. M. (2003). Measuring life-space mobility in community-dwelling older adults. Journal American Geriatric Society, 51, 1610-1614. doi: 10.1046/j.1532-5415.2003.51512.

Carr, D. B., \& O’Neill, D. (2015). Mobility and safety issues in drivers with dementia. International Psychogeriatrics, 27(10), 1613-1622. doi: 10.1017/S104161021500085X. 
Choi, N. G., \& DiNitto, D. M. (2015). Depressive symptoms among older adults who do not drive: Association with mobility resources and perceived transportation barriers. The Gerontologist, 56(3), 432-443. doi: 10.1093/geront/gnu116.

Gustafsson, L., Liddle, J., Liang, P., Pachana, N., Hoyle, M., Mitchell, G., \& McKenna, K. (2012). A driving cessation program to identify and improve transport and lifestyle issues of older retired and retiring drivers. International Psychogeriatrics, 24(5), 794-802. doi: 10.1017/S1041610211002560.

Hunt, L. A., Brown, A. E., \& Gilman, I. P. (2010). Drivers with dementia and outcomes of becoming lost while driving. American Journal of Occupational Therapy, 64, 225-232. doi: 10.5014/ajot.64.2.225.

James, B. D., Boyle, P. A., Buchman, A. S., Barnes, L. L., \& Bennett, D. A. (2011). Life space and risk of Alzheimer disease, mild cognitive impairment, and cognitive decline in old age. The American Journal of Geriatric Psychiatry, 19(11), 961-969. doi: 10.1097/JGP.0b013e318211c219.

Law, M. (1998). Client centered occupational therapy. Thorofare, NJ: SLACK.

Liddle, J., Bennett, S., Allen, S., Lie, D. C., Standen, B., \& Pachana, N. A. (2013a). The stages of driving cessation for people with dementia: needs and challenges. International Psychogeriatrics, 25(12), 2033-2046. doi: 10.1017/s1041610213001464

Liddle, J., Hayes, R., Gustafsson, L., \& Fleming, J. (2014). Managing driving issues after an acquired brain injury: Strategies used by health professionals. Australian Occupational Therapy Journal, 61(4), 215-223. doi: 10.1111/1440-1630.12119.

Liddle, J., Haynes, M., Pachana, N. A., Mitchell, G., McKenna, K., \& Gustafsson, L. (2013b). Effect of a group intervention to promote older adults' adjustment to driving cessation on community mobility: A randomized controlled trial. Gerontologist, 54(3), 409-422. doi: 10.1093/geront/gnt019.

Liddle, J., Tan, A., Liang, P., Bennett, S., Allen, S., Lie, D. C., \& Pachana, N. A. (2016). “The biggest problem we've ever had to face": How families manage driving cessation with people with dementia. International Psychogeriatrics, 28(1), $109-122$. doi: $10.1017 /$ S1041610215001441.

Medical Research Council. (2019). A framework for the development and evaluation of RCTs for complex interventions to improve health. London: MRC. Retrieved from www.mrc.ac.uk/complexinterventionsguidance.

Miles, M. B., \& Huberman, A. M. (1994). Qualitative data analysis: An expanded sourcebook. Thousand Oaks, CA: Sage Publications.

Morris, J. C. (1993). The Clinical Dementia Rating (CDR): Current version and scoring rules. Neurology, 43(11), $2412-2414$. doi: 10.1212/WNL.43.11.2412-a.

O’Neill, D., Neubauer, K., Boyle, M., Gerrard, J., Surmon, D., \& Wilcock, G. K. (1992). Dementia and driving. Journal of the Royal Society of Medicine, 85(4), 199.

Pachana, N. A., Byrne, G. J., Siddle, H., Koloski, N., Harley, E., \& Arnold, E. (2007). Development and validation of the Geriatric Anxiety Inventory. International Psychogeriatrics, 19(1), 103-114. doi: 10.1017/S1041610206003504.

Perkinson, M., Berg-Weger, M., ... \& Morris, J. C. (2005). Driving and dementia of the Alzheimer type: Beliefs and cessation strategies among stakeholders. Gerontologist, 45(5), 676-685. doi: 10.1093/geront/45.5.676.

Proctor, E., Silmere, H., Raghavan, R., Hovmand, P., Aarons, G., Bunger, A., . . \& Hensley, M. (2011). Outcomes for implementation research: Conceptual distinctions, measurement challenges, and research agenda. Administration and Policy in Mental Health and Mental Health Services Research, 38(2), 65-76. doi: 10.1007/s10488-010-0319-7.

Smith, E. R., Broughton, M., Baker, R., Pachana, N. A., Angwin, A. J., Humphreys, M. S., ... \& Hegney, D. (2011). Memory and communication support in dementia: Research-based strategies for caregivers. International Psychogeriatrics, 23(2), 256-263.doi: 10.1017/S1041610210001845.

Scott, T. L., Liddle, J., Mitchell, G., Beattie, E., \& Pachana, N. A. (2019a). Implementation and evaluation of a driving cessation intervention to improve community mobility and wellbeing outcomes for people living with dementia: Study protocol of the 'CarFreeMe' for people with dementia program. BMC Geriatrics, 19(1), 66. doi: 10.1186/s12877-0191074-6.

Scott, T. L., Liddle, J., Pachana, N. A., Beattie, E., \& Mitchell, G. (2019b). Managing the transition to non-driving in patients with dementia in primary care settings: Facilitators and barriers reported by primary care physicians. International Psychogeriatrics, 1-10. doi: 10.1017/S1041610218002326.

Xue, Q. L., Fried, L. P., Glass, T. A., et al. (2008). Life-space constriction, development of frailty, and the competing risk of mortality: The Women's Health and Aging Study I. American Journal of Epidemiology, 167, 240-248. doi: 10.1093/aje/ kwm270.

Yesavage, J. A., Brink, T. L., Rose, T. L., Lum, O., Huang, V., Adey, M., \& Leirer, V. O. (1982). Development and validation of a geriatric depression screening scale: A preliminary report. Journal of Psychiatric Research, 17(1), 37-49. doi: 10.1016/ 0022-3956(82)90033-4.

Yin, R. K. (2003). Case study research: Design and methods (3rd ed.). Thousand Oaks, CA: Sage.

Cite this article: Scott TL, Liddle J, Sidhu R, Mitchell G, Beattie E, Gustafsson L, and Pachana NA (2020). Adaptation of the CarFreeMe driver retirement intervention to provide driving cessation support to older people living with dementia. Brain Impairment 21, 247-258. https://doi.org/10.1017/BrImp.2020.16 